\title{
An Observational Study of Correlation Between Risk Factors- Obesity, Hypertension, Diabetes, Dyslipidemia with Carotid Intima Media Thickness In Patients Above 40 Years Of Age
}

\author{
DR.V.Ushapadmini ${ }^{1}$, DR.Manohari Ramachandran ${ }^{2}$, DR.Kumar Natarajan ${ }^{3}$, \\ Dr.Ravishankar ${ }^{4}$ \\ ${ }^{I}$ M.D.,Senior Assistant Professor,Department of General medicine, Coimbatore medical college, \\ ${ }^{2}$ M.D.,Professor \\ ${ }^{3}$ Professor,Medicine department \\ ${ }^{4}$ M.B.B.S.D.C.H.Senior civil surgeon, Master health checkup5.DR.MuraliM.D.,Professor,Radiology
}

\begin{abstract}
The CIMT is a simple and inexpensive tool which can be used to assess the cumulative effect of atherosclerotic risk factors and it is also an independent predictor of future cardiovascular risk. The International Atherosclerosis project suggests that the atherosclerotic process occurs at the same time in the Carotid, Cerebral and Coronary arteries. Measurement of CIMT of CCA by B mode ultrasound is a suitable noninvasive method to visualize the arterial walls and to monitor the early stages of the atherosclerotic process. The CIMT >1 mm is considered to be Abnormal and >1.2 mm is High risk. Therse is general agreement that the presence of obvious plaque indicates high risk at any age. When there is only IMT without Obvious Plaque then the normal need to be adjusted for Age, Gender and Perhaps even Ethnicity.
\end{abstract}

\section{Introduction}

The following study is about Correlation of various risk factors like Obesity, Diabetes, Hypertension and Dyslipidemia with CIMT in Patients above 40 years of age. The Study, Study group and control group were taken at Coimbatore medical college with Inclusion and Exclusion criteria

AIM OF THE STUDY:

1.To observe the correlation between Various risk factors with CIMT in patients above 40 years of age 2.To Analyse and Correlate already existing CAD And Stroke with CIMT

SUBJECTS

CASE SELECTION: Patients above 40 years attending the master health clinic

INCLUSION CRITERIA: All patients above 40 years with risk factors and patients who already had stroke and CAD

EXCLUSION CRITERIA: All patients less than 40 years of age and patients who had already undergone Carotid end arterectomy

METHODOLOGY: Data from patients aged above 40 years were collected over a period of 3 months and it was correlated with CIMT done by Bmode ultrasound

DATA ANALYSIS:

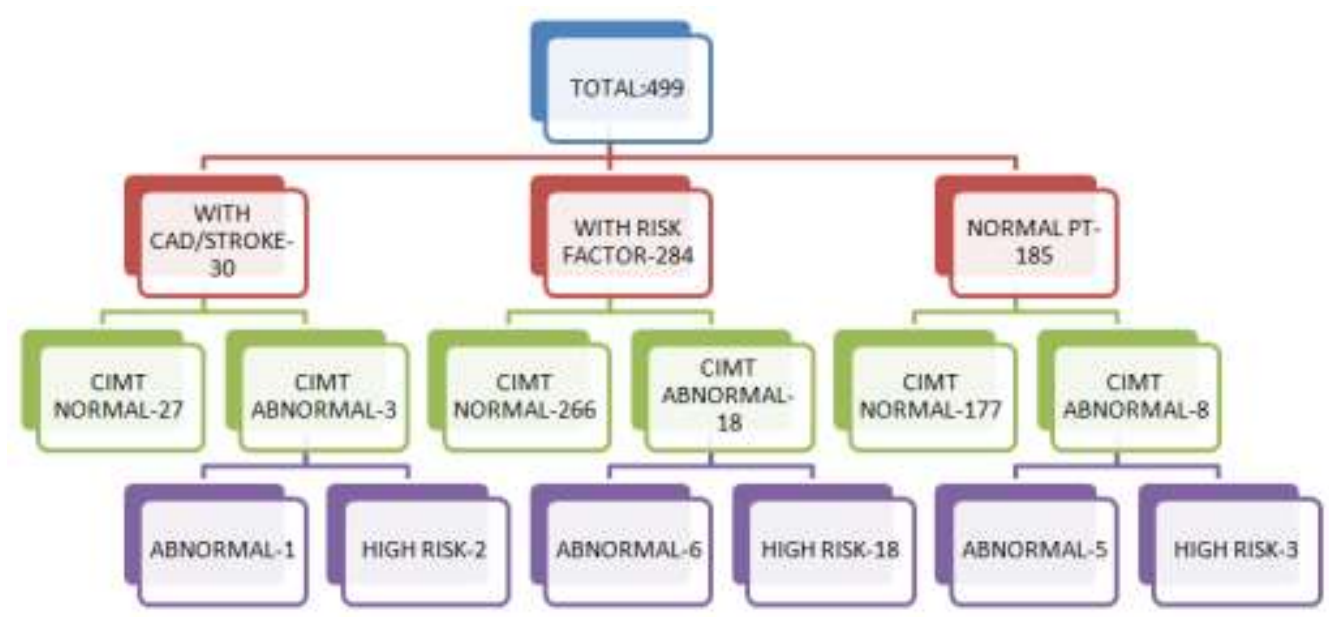

This was the data analysis of our study subjects 


\section{Results}

All analysis where done using chi square test:

I.General comparison between the groups keeping as 2 groups just CIMT is normal or abnormal and 3 group of patient

1. with macrovascular complication

2. with risk factor but no macrovascular complication

3. Normal pt without both risk factor and macrovascular complications

\begin{tabular}{|l|l|l|}
\hline & CIMT NORMAL & CIMT ABNORMAL \\
\hline WITH MVC & 27 & 3 \\
\hline WITH RISK FACTOR & 266 & 18 \\
\hline NORMAL & 177 & 8 \\
\hline
\end{tabular}

The chi-square statistic is 1.8528 . The $p$-value is .395975 . The result is not significant at $p<.05$.

II.Correlate the presence or absence of macrovascular complication in 2 ways

1. CIMT - normal or abnormal

2. CIMT-normal abnormal or high risk

\begin{tabular}{|l|l|l|l|l|}
\hline & \multicolumn{4}{|l|}{ CIMT } \\
\hline MACROVASCULAR COMPLICATION & NORMAL & ABNORMAL & HIGH RISK & TOTAL \\
\hline PRESENT & 27 & 1 & 2 & 30 \\
\hline ABSENT & 443 & 11 & 15 & 469 \\
\hline
\end{tabular}

The chi-square statistic is 1.17 . The p-value is .5571 . This result is not significant at $p<.05$.

Inference: There is no significant difference of macrovascular complication between all 3 groups

\begin{tabular}{|l|l|l|l|}
\hline MVC & ABNORMAL & NORMAL & Marginal Row Totals \\
\hline PRESENT & $3(1.74)[0.91]$ & $27(28.26)[0.06]$ & 30 \\
\hline ABSENT & $26(27.26)[0.06]$ & $443(441.74)[0]$ & 469 \\
\hline Marginal Column Totals & 29 & 460 & 499 \\
\hline
\end{tabular}

The chi-square statistic is 1.0229 . The $\mathrm{p}$-value is .311825 . This result is not significant at $\mathrm{p}<.05$.

Inference: There is no significant difference of macrovascular complication between both groups

II. Correlate the presence or absence of risk factors in 2 ways

1. CIMT - normal or abnormal

2. CIMT-normal or abnormal or high risk

\begin{tabular}{|l|l|l|l|l|}
\hline \multicolumn{4}{|c|}{ CIMT } \\
\hline WITH RISK FACTORS & NORMAL & ABNORMAL & HIGH RISK & TOTAL \\
\hline PRESENT & 281 & 7 & 13 & 301 \\
\hline ABSENT & 189 & 5 & 4 & 198 \\
\hline
\end{tabular}

The chi-square statistic is 1.93 . The $\mathrm{p}$-value is .381 . This result is not significant at $\mathrm{p}<.05$.

Inference: There is no significant difference of influence of risk factors on CIMT between all 3 groups

\begin{tabular}{|l|l|lll|ll|l|}
\hline RISK FACTORS & \multicolumn{2}{|l|}{ ABNORMAL } & \multicolumn{2}{l|}{ NORMAL } & \multicolumn{2}{l|}{ Marginal Row Totals } \\
\hline PRESENT & $20 \quad(17.49)$ & {$[0.36]$} & 281 & $(283.51)$ & {$[0.02]$} & 301 & \\
\hline ABSENT & $9 \quad(11.51)$ & {$[0.55]$} & 189 & $(186.49)$ & {$[0.03]$} & 198 & \\
\hline Marginal Column Totals & 29 & 470 & & $499 \quad$ (Grand Total) \\
\hline
\end{tabular}

The chi-square statistic is 0.9614 . The $\mathrm{p}$-value is .326844 . This result is not significant at $\mathrm{p}<.05$.

Inference: There is no significant difference of influence of risk factors on CIMT between both groups

III. Correlate the presence or absence of obesity/overweight in 2 ways

1. CIMT - normal or abnormal

2. CIMT-normal or abnormal or high risk

\begin{tabular}{|l|l|l|l|l|}
\hline & \multicolumn{2}{l|}{ CIMT } & HIGH RISK & TOTAL \\
\hline OBESITY/OVERWEIGHT & NORMAL & ABNORMAL & 8 & 206 \\
\hline PRESENT & 195 & 3 & 8 & 293 \\
\hline ABSENT & 275 & 9 & 9 & 9 \\
\hline
\end{tabular}


An Observational Study Of Correlation Between Risk Factors-Obesity, Hypertension, Diabetes, ..

The chi-square statistic is 1.55 . The p-value is .460. This result is not significant at $\mathrm{p}<.05$.

Inference: There is no significant difference of influence of bodyweight on CIMT between all 3 groups

\begin{tabular}{|c|c|c|c|}
\hline & ABNORMAL & NORMAL & Marginal Row Totals \\
\hline OBESE/OVERWEIGHT & $\begin{array}{lll}11 & (11.97) & {[0.08]}\end{array}$ & $\begin{array}{llll}195 & (194.03) & {[0]}\end{array}$ & 206 \\
\hline NORMAL WEIGHT & $\begin{array}{lll}18 & (17.03) & {[0.06]} \\
\end{array}$ & $\begin{array}{llll}275 & (275.97) & {[0]} \\
\end{array}$ & 293 \\
\hline Marginal Column Totals & 29 & 470 & 499 (Grand Total) \\
\hline
\end{tabular}

The chi-square statistic is 0.1427 . The $\mathrm{p}$-value is .705634 . This result is not significant at $\mathrm{p}<.05$.

Inference: There is no significant difference of influence of bodyweight on CIMT between both groups

IV. Correlate the presence or absence of hypertension in 2 ways

1. CIMT - normal or abnormal

2. CIMT-normal or abnormal or high risk

\begin{tabular}{|l|l|l|l|l|}
\hline & \multicolumn{4}{|l|}{ CIMT } \\
\hline HYPERTENSION & NORMAL & ABNORMAL & HIGH RISK & TOTAL \\
\hline PRESENT & 97 & 0 & 4 & 101 \\
\hline ABSENT & 373 & 12 & 13 & 398 \\
\hline
\end{tabular}

The chi-square statistic is 3.21. The p-value is .2009. This result is not significant at $p<.05$.

Inference: There is no significant difference of influence of presence of hypertension on CIMT between all 3 groups

\begin{tabular}{|l|l|l|l|l|}
\hline & ABNORMAL & NORMAL & Marginal Row Totals \\
\hline HYPERTENSION & $4(5.87)[0.6]$ & $97 \quad(95.13)[0.04]$ & 101 \\
\hline NORMAL BP & $25(23.13)[0.15]$ & $373 \quad(374.87)[0.01]$ & 398 & \\
\hline Marginal Column Totals & 29 & 470 & $499 \quad$ (Grand Total) \\
\hline
\end{tabular}

The chi-square statistic is 0.7928 . The $\mathrm{p}$-value is .373255 . This result is not significant at $\mathrm{p}<.05$.

Inference: There is no significant difference of influence of hypertension on CIMT between both groups

V. Correlate the presence or absence of macrovascular complication in 2 ways

1. CIMT - normal or abnormal

2. CIMT-normal or abnormal or high risk

\begin{tabular}{|l|l|l|l|l|}
\hline & \multicolumn{4}{|l|}{ CIMT } \\
\hline DIABETES MELITUS & NORMAL & ABNORMAL & HIGH RISK & TOTAL \\
\hline PRESENT & 97 & 7 & 6 & 110 \\
\hline ABSENT & 373 & 5 & 11 & 389 \\
\hline
\end{tabular}

The chi-square statistic is 11.470229. The $\mathrm{p}$-value is .0032 . This result is significant at $\mathrm{p}<.05$.

Inference: There is significant difference of influence of diabetes mellitus on CIMT between all 3 groups

With chi square value of 11.47 the patients with diabetes mellitus have 11 times more risk of ending up with high risk level of CIMT compared to both abnormal and normal level, which show pt with DM may need intervention and frequent measuring of CIMT

\begin{tabular}{|l|l|l|l|l|}
\hline & \multicolumn{2}{|l|}{ ABNORMAL } & NORMAL & \multicolumn{2}{l|}{ Marginal Row Totals } \\
\hline DM & $13(6.39) \quad[6.83]$ & $97(103.61) \quad[0.42]$ & 110 \\
\hline NORMAL & $16(22.61) \quad[1.93]$ & $373(366.39) \quad[0.12]$ & 389 & \\
\hline Marginal Column Totals & 29 & 470 & $499 \quad$ (Grand Total) \\
\hline
\end{tabular}

The chi-square statistic is 9.3004 . The $\mathrm{p}$-value is .002291 . This result is significant at $\mathrm{p}<.05$.

Inference: There is significant difference of influence of DM on CIMT between both groups

With chi square value of 9.37 the patients with diabetes mellitus have times more risk of ending up with abnormal level (either abnormal or high risk) of CIMT compared to both abnormal and normal level, which show pt with DM may need intervention and frequent measuring of CIMT 
VI. Correlate the presence or absence of dyslipidemia complication in 2 ways

1. CIMT - normal or abnormal

2. CIMT-normal or abnormal or high risk

\begin{tabular}{|l|l|l|l|l|}
\hline & \multicolumn{4}{|l|}{ CIMT } \\
\hline DYSLIPIDEMIA & NORMAL & ABNORMAL & HIGH RISK & TOTAL \\
\hline PRESENT & 26 & 0 & 1 & 27 \\
\hline ABSENT & 444 & 12 & 16 & 472 \\
\hline
\end{tabular}

The chi-square statistic is 0.71 . The $\mathrm{p}$-value is .7012. This result is not significant at $\mathrm{p}<.05$.

Inference: There is no significant difference of influence of dyslipidemia on CIMT between all 3 groups

\begin{tabular}{|l|l|l|l|}
\hline & ABNORMAL & NORMAL & Marginal Row Totals \\
\hline DYSLIPIDEMIA & $1 \quad(1.57)[0.21]$ & $26(25.43)[0.01]$ & 27 \\
\hline NORMAL & $28(27.43)[0.01]$ & $444(444.57) \quad[0]$ & $472 \quad$ \\
\hline Marginal Column Totals & 29 & 470 & 499 (Grand Total) \\
\hline
\end{tabular}

The chi-square statistic is 0.2317 . The $\mathrm{p}$-value is .630262 . This result is not significant at $\mathrm{p}<.05$.

Inference: There is no significant difference of influence of dyslipidemia on CIMT between both groups

VII. Correlate the presence or absence of plaque in 2 ways

1. CIMT - normal or abnormal

2. CIMT-normal or abnormal or high risk

\begin{tabular}{|l|l|l|l|l|}
\hline & \multicolumn{4}{|l|}{ CIMT } \\
\hline IMPRESSION & NORMAL & ABNORMAL & HIGH RISK & TOTAL \\
\hline PLAQUE & 24 & 1 & 8 & 33 \\
\hline NSP & 446 & 11 & 9 & 466 \\
\hline
\end{tabular}

The chi-square statistic is 46.81 . The p-value is $<0.001$. This result is significant at $\mathrm{p}<.05$.

Inference: There is significant difference of influence of plaque on CIMT between all 3 groups

With odds ratio of 46.81 patient with plaque has 47 time more risk of having an high risk of level of CIMT thickness, for which intervention like endaterectomy may be necessary

\begin{tabular}{|l|l|l|ll|}
\hline & CIMT ABNORMAL & CIMT NORMAL & Marginal Row Totals \\
\hline PLAQUE & $9(1.92)[26.15]$ & $24(31.08)[1.61]$ & 33 & \\
\hline NSP & $20(27.08)[1.85]$ & $446(438.92) \quad[0.11]$ & 466 & \\
\hline Marginal Column Totals & 29 & 470 & $499 \quad$ (Grand T \\
\hline
\end{tabular}

The chi-square statistic is 29.7329 . The $p$-value is 0.001 this result is significant at $p<.05$

Inference: There is significant difference of influence of presence of plaque on CIMT between both groups

With odds ratio of 29.73, patients with plaque has 30 times more risk of having an high risk of level of CIMT thickness, for which intervention like endarterectomy may be necessary

To concise patient with abnormal (both abnormal and high risk group) may have 30 times risk and patient with high risk levels have 47 times more chance of ending up with plaque needing intervention.

\section{Conclusions}

1. Patients with Diabetes Mellitus have a strong correlation with CIMT and they need frequent monitoring with B mode ultrasound

2. Patients with plaques have high risk of developing significant carotid intima media thickness

3. Other risk factors like Obesity,Dyslipidemia And Hypertension do not correlate with CIMT Values 